$$
\text { I. }
$$

\title{
Derecho humano al MEDIO AMBIENTE
}





\section{Derecho a un medio ambiente sano y ecológicamente equilibrado}

$\mathrm{Z}^{1}$ ser humano es un ser con capacidad racional que manifiesta Ecada una de sus acciones para beneficio propio o común, los medios para poder satisfacer sus intereses y cubrir sus necesidades pueden variar de acuerdo a cada uno de ellos por lo que los recursos naturales representan para él un medio que le permite subsistir, convivir y aprovechar el beneficio que le proporcionan otros seres del medio, aunado a eso le permite manifestarse en una relación con otros individuos de su misma especie los cuales en su conjunto se adaptan al medio en el que se encuentren.

El medio ambiente proporciona al sujeto una serie de elementos naturales primarios y secundarios que alimentan la supervivencia del individuo dentro de una sociedad, permitiéndole ejercer un "poder" sobre el recurso natural que emplea con el objeto de "ser" y "pertenecer" a un grupo social, a una sociedad, a un sector caracterizado por uno o varios factores que influyen a través de la representación y reproducción social ${ }^{2}$.

En la presencia de transición de un período cíclico, en un primer momento el hombre se adaptó a su medio, posteriormente existió una integración entre el individuo y el entorno, más tarde se fue despojando de una visión integradora con su medio, en donde el

2 Dowdor, Ladislau, La reproducción social, 1ra. Ed., México, siglo XXI, 1999, pp. 360-361. 
hombre dejó de adaptarse al mismo, hoy día el hombre acopla el medio natural según sus intereses y necesidades.

Es decir, los grupos humanos pasaron de ser nómadas a sedentarios a través de los asentamientos en diversos contextos que les ofrecía el medio; propiciando una sociedad estructurada ${ }^{3}$ en aspectos sociales, culturales, políticos y económicos, permitiéndoles un desarrollo primitivo a uno cada vez más moderno y sofisticado en el cual la economía empezó a tener una intervención que generó nuevos contextos como el actual modelo económico.

Se ocupó de crear y satisfacer de forma pronta recursos o instrumentos que le concedieran un trabajo menos tardado y con mayor provecho, el cual se fue desarrollando y evolucionando por medio de la ciencia y tecnología creando un escenario de producción dispar entre los aspectos sociales y ambientales.

En ese escenario de producción los retos que afrontan las sociedades refieren a las formas de organización y valoración del sistema; el cual pasa de un medio de producción desaprovechado en recursos naturales a uno en el que en el siglo XXI nos inserta a una integración y convivencia con el medio ambiente de forma directa e indirecta a través de una economía sustentable, una economía denominada por las propias sociedades como una economía verde ${ }^{4}$.

La visión del medio natural como proveedor inagotable a proveedor agotable crea incertidumbre a nivel global ya que las grandes potencias se movilizan a países con zonas que permiten el control y manejo de los recursos naturales y desechos sin control o intervención alguno de las autoridades correspondientes como es el caso de China ${ }^{5}$, país en que por causa de escasa normatividad

3 Weber, Max, Estructuras de poder, 4ta. Ed., México, FONTAMARA, 2012, p. 45.

4 PNUMA describe la economía verde como "aquella economía que resulta en un mejor bienestar humano y equidad social, reduciendo significativamente los riesgos ambientales y las escaseces ecológicas". Puede ser considerada como una que es baja en carbono, eficiente en recursos y socialmente inclusiva. http://www.unep.org/es/rolac/econom\%C3\%ADa-verde y http://www.unep.org/greeneconomy/

5 Los principales problemas contaminantes del medio natural para China son contenido del dióxido de azufre, polvo de la atmósfera superior a la norma establecida por el Estado. Contaminación del agua de ríos, lagos y mares a causa de sustancias tóxicas, el manto freático ha descendido año con año, se ha dañado los bosques, pastos y aguas. Lo anterior, es derivado del empleo de metales pesados y desechos industriales. Recuperado de: Food and Agriculture 
jurídica en lo respectivo a el cuidado, la preservación, la mitigación, la responsabilidad de daño al medio ambiente y los niveles de contaminación son cada vez mayor, a su vez la mano de obra barata da pauta a que diversas empresas se alojen para la producción de mercancía.

Lo que conlleva a la escasa intervención, gestión o acceso a un derecho humano como lo es el medio ambiente sano, que no debe dejar ausente la interdependencia e indivisibilidad con los derechos a la alimentación, el agua potable, la salud, la vivienda entre otros.

Estos aspectos involucran la condición de bienestar y desarrollo para un individuo en caso de alterarse alguno de ellos, se anula o no existe gestión alguna para el acceso de estos elementos vitales en el desarrollo integral del sujeto, habiendo entonces ausencia de obligación por parte del Estado para promover, respetar, proteger y garantizar los elementos mínimos de cada derecho, incluyendo la accesibilidad, la disponibilidad y la adecuación ${ }^{6}$, derechos que integran las obligaciones establecidas en los tratados internacionales.

En el siguiente gráfico se plasma una idea central de la función del individuo, persona o sujeto social desde su origen a lo que podríamos decir su evolución con base al constructo social, económico y ambiental. El gráfico denota la dinámica del individuo de forma particular y colectiva en su proceso de adaptación a su medio conjugada con las estructuras social, cultural, política y económica que sientan la base de las instituciones sociales de hoy día.

Organization of the United Nations (FAO), "China's environment policy", Revista Unasylva, EE.UU., No. 134, vol., 33, 1981.

6 Gómez Trejo, Omar, Los derechos a la alimentación, al agua, a la salud y a la vivienda contenidos en el artículo 4to. Constitucional a la luz del Derecho Internacional de los Derechos Humanos en México, en Ferrer Mac-Gergor Poisot, Eduardo, Caballero Ochoa, José Luis, et. al. Derechos Humanos en la Constitución: Comentarios de Jurisprudencia Constitucional e Interamericana, México, UNAM-Suprema Corte-Konrad Adenauer Stiftung, 2013, p. 582. 


\section{Gráfico 1. Trinomio: individuo-medio ambiente}

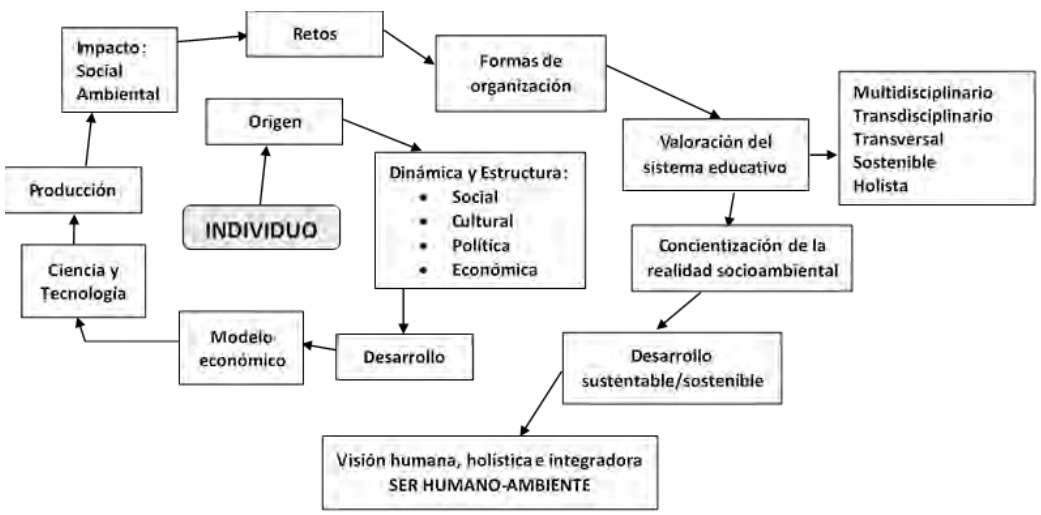

Fuente: Elaboración propia.

El derecho humano a un medio ambiente sano y ecológicamente equilibrado implica factores de vulnerabilidad, daños y violaciones que deben legitimar el acceso a la justicia de forma efectiva.

El reconocimiento y validez de las normas de origen externo e interno dan pauta para conocer, reconocer, ejercer y garantizar el derecho a un medio ambiente sano a través de una justicia transicional ${ }^{7}$ que aborda los conflictos ambientales mediante la inclusión y participación activa de las partes involucradas en los conflictos ambientales.

\section{Medio ambiente sano}

El binomio de la relación ser humano-medio ambiente establece elementos de forma gradual y sustantiva de la interpretación y alcance de lo que se constituye como medio ambiente; el cada vez más complejo panorama global de la repercusión del conflicto

7 Naciones Unidas refiere que la justicia transicional es aquella variedad que conlleva procesos y mecanismos asociados con la intención de la sociedad por resolver problemas o situaciones de conflicto de mediana a gran escala, con el objeto de que los responsables acrediten la responsabilidad de sus actos, exista justicia y se logre la reconciliación. Véase Naciones Unidas, Justicia transicional y derechos económicos, sociales y culturales, Nueva York y Ginebra, 2014, p. 5. 
ambiental en el quehacer físico-biótico, repercute en la integración de una cultura sustentable y por lo tanto en el abordaje y tratamiento de los conflictos de carácter medio ambiental.

En líneas siguiente se describe "medio ambiente" desde el ámbito de competencia internacional y nacional, siendo este el referente de interpretación de análisis del derecho humano al medio ambiente sano que se aborda.

Naciones Unidas lo declara como el conjunto de componentes físicos, químicos, biológicos y sociales capaces de causar efectos directos o indirectos, en un plazo corto o largo, sobre los seres vivos y las actividades humanas ${ }^{8}$. Estos elementos se integran de forma interrelacionada propiciando que sus acciones condicionen la supervivencia de vida en el planeta mismos pueden ser alterados, modificados y/o condicionados por el ser humano a través de las actividades de su quehacer cotidiano.

En 1987 Naciones Unidas ${ }^{9}$ plantea el desarrollo sostenible como aquel "que satisface las necesidades del presente sin comprometer la habilidad de las generaciones futuras para satisfacer sus propias necesidades." Expone de esa manera acciones de responsabilidad en el uso de los recursos naturales.

En México la Ley General del Equilibrio Ecológico y la Protección al Ambiente (LGEEPA) ${ }^{10}$ define al ambiente como el conjunto de elementos naturales y artificiales o inducidos por el hombre que hacen posible la existencia y desarrollo de los seres humanos y demás organismos vivos que interactúan en un espacio y tiempo determinado, refiere un sistema vivo en conjunto dependiente del medio natural.

La enciclopedia de Derechos del Pueblo Mexicano ${ }^{11}$ señala que en el caso del medio ambiente se trata de asegurar el poder disfrutar de

8 Definición derivada de la Conferencia de las Naciones Unidas sobre Medio Ambiente en Estocolmo en el año de 1972.

9 En 1987 la Comisión Mundial del Medio Ambiente y del Desarrollo elabora la definición de desarrollo sostenible. Véase http://www.un-documents.net/wced-ocf.htm

10 Ley Publicada en el Diario Oficial de la Federación el 28 de enero de 1988, texto vigente, últimas reformas publicadas DOF 05-11-2013.

11 Madrazo Jorge y Cottom, artículo $4^{\circ}$, Enciclopedia de Derechos Humanos del Pueblo Mexicano, México a través de sus Constituciones, Tomo1, artículos $1^{\circ}$-15, México, Porrúa, SCJN, IFE, Legislatura Cámara de Diputados, Senado de la República, 2012, p. 551. 
una biosfera con las características físicas y biológicas mínima para una buena calidad de vida. A partir del mínimo se crea un parámetro de aseguramiento de buena o mala calidad de vida determinada en el acceso a disfrutar la biosfera, de forma indirecta lleva a considerar la sostenibilidad de un medio que se integra de factores físicos y biológicos.

El medio ambiente y desarrollo sustentable refiere a la gestión o administración racional y efectiva de todos aquellos recursos naturales que considere de forma activa establecer, mejorar $y$ mantener el bienestar de desarrollo y crecimiento de la población presente sin comprometer la calidad de vida y bienestar de la población futura.

El vínculo entre la sociedad y la naturaleza se establece en dos factores: "el conjunto de las acciones humanas que inciden sobre el sistema ecológico natural y el conjunto de efectos ecológicos generados en la naturaleza y que inciden sobre el sistema social ${ }^{12}$ ".

A los derechos de primera y segunda generación ${ }^{13}$ que caracterizó la modernidad y búsqueda de justicia social como bien supremo del individuo y del ciudadano, se sumó el derecho al medio ambiente como un aspecto base del derecho a una vida digna.

En el marco jurídico internacional en materia ambiental los derechos humanos tienen existencia en la tercera generación ${ }^{14}$ (violaciones a los derechos colectivos) en los cuales se enmarcan la violación del derecho al desarrollo; a disfrutar de un medio ambiente sano y ecológicamente equilibrado; daño ecológico; derecho a disfrutar del patrimonio común de la humanidad; a la paz y a ser diferente; considerándose de carácter colectivo y difuso, por

12 Gallopín, Gilberto, Ecología y ambiente, los problemas del conocimiento y la perspectiva ambiental del desarrollo, México, siglo XXI, 1986, p. 161.

13 Herrera Carrillo, Ricardo, Las corporaciones autónomas regionales y la justicia ambiental, en Justicia Ambiental, las acciones judiciales para la defensa del medio ambiente, Colombia, CAR, 2001, p. 17.

14 La primera generación surge con la Revolución Francesa, constituida por derechos civiles y políticos, siglo XVIII y XIX. La segunda generación surge con la Revolución Industrial, conformada por derechos colectivos económicos, sociales y culturales, siglo XIX y XX. La tercera generación surge con las necesidades constituidas por los derechos de los pueblos o de solidaridad siglo XX y XXI (paz, desarrollo y medio ambiente), engloban los dos derechos civiles, políticos, económicos, sociales y culturales, aunándose los de cooperación entre los pueblos. 
lo cual debe reestructurase o crear nuevas formas alternativas de resolver todos aquellos conflictos que han sido conducidos de forma tradicional en la justicia para trascender a alternativas con criterios de equivalencia.

Los criterios y derechos integrados en la tercera generación de derechos humanos derivan de una serie de factores sociales, económicos, culturales y políticos para el desarrollo y crecimiento de nuevas sociedades; teniendo énfasis a partir de acontecimientos internacionales que dieron pauta a identificar que lo acontecido en un contexto concreto socio ambiental, impacta en otro contexto, siendo que las mismas causas de alteración eran suscitadas por el mismo factor. Por lo que, se considera importante destacar las características que refieren o conceptualizan cada uno de las violaciones y derechos colectivos concernientes al tema ambiental ${ }^{15}$.

Los derechos humanos relacionados con el medio ambiente se encuentran establecidos en los tratados básicos de derechos humanos e incluyen el derecho a un medio ambiente sano y saludable ${ }^{16}$ :

- Derecho a un nivel alto de salud.

15 La LFRA, artículo 2, comprende en el caso del bien colectivo términos que señalan el motivo de la vulnerabilidad, abuso y violación del derecho humano al medio ambiente:

Violación del derecho al desarrollo. Refiere a las conductas de acción u omisión en la que se reprime la participación activa e inclusiva de los pueblos para el desarrollo económico, social, cultural y político de los mismos.

Daño ecológico. Se conceptualiza de acuerdo a las acciones de alteración dolosa o culposa mediante acciones u omisiones.

Daño al ambiente. La Ley Federal de Responsabilidad Ambiental (LFRA) en México señala que es toda aquella pérdida, cambio, deterioro, menoscabo, afectación o modificación adversos y mensurables del hábitat, de los ecosistemas, de los elementos y recursos naturales, de sus condiciones químicas, físicas o biológicas, de las relaciones de interacción que se dan entre éstos, así como de los servicios ambientales que proporcionan. El daño indirecto, se considera aquel daño que en una cadena causal no constituye un efecto inmediato del acto u omisión que es imputado a una persona.

Estado base. Condición en la que se habrían hallado los hábitats, los ecosistemas, los elementos y recursos naturales, las relaciones de interacción y los servicios ambientales, en el momento previo inmediato al daño y de no haber sido éste producido (LFRA).

Al respecto, todo aquel que viole o vulnere ese derecho, será sometido a una acción de alteración dolosa o culposa mediante acciones u omisiones.

16 Cossío Díaz, José Ramón y Meza Fonseca, Emma (coords.), Delitos contra el ambiente u gestión ambiental en el Código Penal Federal, México, Bosch, 2014, p. 46. 
- Derecho a un desarrollo y progreso sustentable ecológico.

- Derecho a una vida digna a partir de un nivel apropiado que considere los básicos de acceso a la alimentación y agua potable.

- Derecho del niño en cuanto a tener un hábitat que le permita un conveniente desarrollo y crecimiento físico y mental.

- Derecho a la participación democrática y equitativa de los ciudadanos para la toma de decisiones concernientes al medio ambiente.

- Derecho a la protección de no discriminación.

- Derecho a la educación e información relativas y vinculadas en salud y medio ambiente.

- Derecho de compartir los avances y progreso científico.

- Derecho a seguridad social.

- Derecho de acceso a la información.

Se trata de concebir el medio ambiente como aquel que deriva del derecho ambiental y que a partir del mismo se vincula con derechos humanos y garantías fundamentales que velan por el interés del bienestar de los ciudadanos.

\section{Justicia ambiental}

La afectación o ausencia de garantizar los derechos humanos en materia ambiental suscitó un abordaje a nivel global que ha ido concretándose en una serie de tratados, cumbres, programas, entre otros, que suponen de forma general y específica la vulnerabilidad del medio ambiente sano para la sociedad en sus diversas dimensiones a partir del principio de justicia ambiental ${ }^{17}$ atendiendo los factores esenciales de explotación y sostenibilidad de la correlación existente entre propiedad-desarrollo sostenible y medio ambiente sano ${ }^{18}$.

17 El concepto de justicia ambiental surge en los años setenta, con base a los movimientos que se oponían a la desigual y racialmente discriminatoria distribución espacial de los residuos peligrosos y las industrias contaminantes en los EE.UU. Véase Ríos Sarmiento, Melissa; Aguirre Fajardo, Alejandra María; Gonzaga Valencia Hernández, Javier, "Desafíos de la justicia ambiental y el acceso a la justicia ambiental en el desplazamiento ambiental por efectos asociados al cambio climático", Revista Luna Azul, núm. julio-diciembre, 2015, p. 335.

18 Boletín Informativo de Justicia Ambiental. Agencia de Protección Ambiental de los Estados Unidos, Administración y Gerencia de Recursos (3103), EPA/200-F-9-004, agosto 1994, Oficina de Justicia Ambiental. La EPA señala que la misión de justicia ambiental 
La Agencia de Protección Ambiental de Estados Unidos (APAEU) $)^{19}$ emplea la justicia ambiental como "el tratamiento justo de personas de todas las razas, culturas, ingresos y niveles educativos con respecto al desarrollo e implementación de leyes, reglamentación y políticas ambientales" este concepto configura equidad e igualdad de acceso en la implementación de la normativa ambiental.

Javier Gonzaga ${ }^{20}$ describe el derecho de acceso a la justicia ambiental por su configuración como derecho autónomo, establecido en un instituto legal dotado de contenido sustancial ${ }^{21}$ y procedimental $^{22}$ que lo hace independiente en su estatuto jurídico pero interdependiente con otros institutos jurídicos que reconocen los derechos humanos afectados como consecuencia del deterioro ambiental y la inequitativa distribución de los recursos que ante tales hechos vulneran o violan derechos y garantías de bien común e individual.

Este tipo de justicia implica tener acceso al mismo ${ }^{23}$, es decir aborda el compuesto de procedimientos administrativos y judiciales

para lograr una razonable protección del ambiente y que ningún sector de la población, no importa su raza, etnicidad, cultura, o ingreso compartan el peso desproporcionado de las consecuencias de contaminantes ambientales. El presidente Clinton firmó el 11 de febrero de 1994, la Orden Ejecutiva 12898, comprometiendo al Gobierno Federal con los principios de Justicia Ambiental. Lo anterior significa un ejemplo de las estrategias de líneas de enlace ambiental que procuran desde el poder ejecutivo asegurar que todas las personas reciban el beneficio total de comunidades limpias y sostenidas.

19 Véase https://espanol.epa.gov/espanol/terminos-j

20 Valencia Hernández, Javier Gonzaga, "El derecho de acceso a la justicia ambiental y sus mecanismos de aplicación en Colombia", tesis doctoral, Universidad de Alicante, 2011, p. 206. 21 Se refiere a lo sustantivo como el conjunto de reivindicaciones políticas y sociales, que se aloja en un entorno ecológico y social de forma inclusiva viéndose desde una perspectiva complementaria y no separada o individualizada, dependientes uno del otro con carácter de sujetos y no como objetos.

22 Lo procedimental recae en el aspecto jurídico el cual establece los derechos de forma material que a su vez determinan los procedimientos que se requieren para reconocerlos en el momento que se vulneren o violen; asimismo funcionan como preventivos al momento de establecer las consecuencias jurídicas que se tiene al momento de existir una conducta o acción que perjudique a otros; funciona como aquel que reconoce los derechos como el de consulta previa, acceso a la información, a un medio ambiente sano, a una vida digna; es decir reconoce todos los derechos individuales y colectivos.

23 Valencia Hernández, Javier Gonzaga, et. al., "Desafíos de la justicia ambiental y el acceso a la justicia ambiental en el desplazamiento ambiental por efectos asociados al cambio climático", Revista Luna Azul, Colombia, núm. 41, julio-diciembre de 2015, pp. 339-340, http:// www.redalyc.org/articulo.oa?id=321739268018 
que protejan, conservan y garanticen la defensa del medio ambiente que se simplifica como derecho ambiental. Este concepto presupone la garantía del derecho ambiental con base a un procedimiento institucionalizado en un sistema estructural-funcional con carácter de poder legítimo.

La justicia ambiental parte no sólo de asegurar la protección de los riesgos medioambientales relativos a la salud y calidad de vida; sino que puedan disfrutar el derecho a vivir en un medio ambiente sano, independientemente de su etnia, género, edad o nivel de ingresos económicos ${ }^{24}$.

Autores como Tower ${ }^{25}$ y Wenz ${ }^{26}$ aplican la justicia ambiental desde el marco de escala humana relacionada a la justicia distributiva; la equidad refleja para ellos, un beneficio común a partir de la participación social y toma de decisiones. Se basa en un proceso singular y plural de equidad y sustentabilidad que debe apoyarse de políticas públicas ${ }^{27}$ que impliquen la sustentabilidad considerando los aspectos sociales, económicos, políticos y culturales.

Este concepto remite a considerar una justicia de visión equitativa, participativa e inclusiva sin exclusión alguna que promueva una justicia preventiva, de mitigación y compensación correspondiente a partir de políticas públicas que en consenso con la sociedad atribuyan medidas acordes a la realidad en la que estén inmersos las estructuras e instituciones sociales.

24 Roblero González, Juan Ángel, et. al., "El acceso a la justicia ambiental y la posibilidad de implantación de tribunales ambientales en Chiapas, México" México, Revista Ra Ximhai, núm. 2, vol. 8, mayo-agosto de 2012, pp. 175-180, http://www.redalyc.org/articulo. oa? id=46123333018

25 Towers, G., "Applying the Political Geography of Scale: Grassroots Strategies and Environmental Justice", The professional geographer, 2000, Vol. 52, Núm. 1, pp. 23-36.

26 Wenz, P.S. Environmental Justice, State University of New York Press, 1988, Albany.

27 Véase Galindo Mendoza, María G., et. al., "Justicia Ambiental. Entre la utopía y la realidad social Culturales" México, Revista Culturales, núm. 1, vol. III, enero-junio de 2015, p. 244, http://www.redalyc.org/articulo.oa?id=69438994008 Los autores consideran que la justicia ambiental debe entenderse como un paradigma complejo, que tutela el uso sustentable de los recursos naturales, vinculándolos a las políticas públicas, para que en éstas se inserten aspectos de protección a los derechos fundamentales relacionados, así como participación de los actores para incidir en el proceso de toma de decisiones y que trascienda en la resolución de problemas ambientales. 


\section{Derecho al agua}

Derivado de la materia de Derecho ambiental respecto al cuidado del medio ambiente a partir de las garantías y su acceso como derecho; resulta de interés prioritario y de seguridad nacional e internacional el derecho al agua a partir del simple hecho de ser parte esencial y vital para todos los organismos que habitan en este planeta.

En cuanto a la visión o perspectiva jurídica hoy día se reconoce como derecho humano el derecho al agua en cuanto al acceso al agua potable ya que al ser un recurso vital y limitado está creando estrés hídrico a nivel global que conlleva a considerar de forma política y gubernamental, políticas públicas que reconsideren la gestión integral del agua.

Resulta entonces que el interés de acceso a este derecho se configura de forma macro mediante los tratados o instrumentos internacionales a una aplicación micro en un contexto nacional, estatal o regional. La comprensión resulta ser compleja ya que implica activar la participación e inclusión activa de la ciudadanía para la toma de decisiones aun cuando mayormente resulta ser un derecho transgredido.

Como ya se ha enunciado este derecho tiene estrecho vínculo con otros derechos humanos, mismos que al momento de presentarse pueden manifestarse con mayor grado de vulnerabilidad o exclusión de acuerdo al grupo social que se trate, por ejemplo, el grupo vulnerable como los pueblos indígenas ${ }^{28}$ son más susceptibles de padecer de menor atención.

En el caso de México es recurrente la violación de derecho a la propiedad, al desarrollo sustentable, libre autodeterminación, identidad cultural, al derecho a la consulta previa de los pueblos y comunidades indígenas ${ }^{29}$ que es una de las mayores causas de

28 Heller, Léo, Me parece que las poblaciones rurales tienen menos prioridad que las urbanas. Los que viven en las periferias tienen menos prioridad que los que viven en la parte central de las ciudades. Los grupos indígenas menos que los no indígenas. Hay cierto patrón de desigualdad o inequidad en el acceso de los servicios. Hay una exclusión de las poblaciones en condiciones más vulnerables. Véase http://www.agua.unam.mx/noticias/2017/nacionales/ not_nac_mayo $14 . h t m l$

29 En el caso de México véase DOF: 12/08/2016. RECOMENDACIÓN General No. 27/2016 sobre el derecho a la consulta previa de los pueblos y comunidades indígenas de la República Mexicana. http://www.dof.gob.mx/nota_detalle.php?codigo=5447796\&fecha=12/08/2016 
conflicto manifiesto debido a que los pueblos indígenas no son considerados para la toma de decisiones concerniente al modelo de desarrollo que desean.

\section{Normas de origen externo}

Uno de los aspectos vitales enmarcados dentro del medio ambiente sano y equilibrado es el recurso hídrico el cual es de importancia para la sobrevivencia de las especies en todos los ecosistemas.

Enunciar la importancia del derecho al agua supone la apertura de un panorama de derechos que permite el acceso de forma directa e indirecta para el fortalecimiento y vínculo de otros, persistiendo la dependencia tácita de este derecho.

$\mathrm{Al}$ respecto es necesario resaltar el valor que se tiene y la garantía que se puede llegar a concebir a través de los instrumentos internacionales del derecho al agua de grupos vulnerables debido a que en ocasiones se invoca circunstancia y/o factores endógenos y exógenos que alteran las relaciones sociales y por consecuencia en las conductas y acciones manifestadas en su forma de vida, originando nuevos escenarios derivado de los procesos de vulnerabilidad o riesgo.

Con esos procesos se conjugan otros aspectos de las garantías de un medio ambiente sano, el desarrollo de una vida digna para las personas de forma sustentable e integral.

Otros derechos vulnerados de la comunidad indígena son la toma de decisiones; el acceso a la información; el derecho a un medio ambiente sano; la prevalencia de mantener sus orígenes ya que parece ser un atentado contra su cultura que pone en riesgo la desaparición de la misma, así como el derecho al libre desarrollo; entre otros.

Por tal motivo, se considera necesario enunciar todos aquellos instrumentos de origen internacional, que permitan considerar lo establecido en los mismos y con fundamento en ello se puedan abordar aspectos esenciales que garanticen al derecho al agua; así como manifestar o invocar el acceso de todo aquel derecho que no sea respetado y por consecuencia vulnere o ponga en riesgo la 
permanencia de alguna comunidad indígena o en su caso que no exista el cuidado del medio ambiente de forma sostenible.

\section{Instrumentos internacionales}

El primer instrumento internacional es el establecido en el sistema universal de protección de Derechos humanos, en la Declaración Universal, artículo 25, reconociendo de forma implícita el derecho al agua $^{30}$. "Toda persona tiene derecho a un nivel de vida adecuado que le asegure, así como a su familia, la salud y el bienestar, y en especial la alimentación".

La Declaración da pauta para establecer la importancia de la "soberanía permanente sobre los recursos naturales"31 en el que la misma no debe comprometerse por nada que no vaya afín a los valores y bien común de la propia sociedad; el ejercicio de la soberanía deberá responder de forma integral, sustentable y equitativa al desarrollo ${ }^{32}$.

30 Declaración Universal de los Derechos Humanos Asamblea General de las Naciones Unidas Aprobada el 10 de diciembre de 1948.

Artículo. - 25. 1. Toda persona tiene derecho a un nivel de vida adecuado que le asegure, así como a su familia, la salud y el bienestar, y en especial la alimentación, el vestido, la vivienda, la asistencia médica y los servicios sociales necesarios; tiene asimismo derecho a los seguros en caso de desempleo, enfermedad, invalidez, viudez, vejez u otros casos de pérdida de sus medios de subsistencia por circunstancias independientes de su voluntad. 2. La maternidad y la infancia tienen derecho a cuidados y asistencia especiales. Todos los niños, nacidos de matrimonio o fuera de matrimonio, tienen derecho a igual protección social.

31 Resolución 1803 (XVII) de la Asamblea General de la ONU del 14 de diciembre de 1962, Declara lo siguiente:

1. El derecho de los pueblos y de las naciones a la soberanía permanente sobre sus riquezas y recursos naturales debe ejercerse en interés del desarrollo nacional y del bienestar del pueblo del respectivo Estado.

[...]

7. La violación de los derechos soberanos de los pueblos y naciones sobre sus riquezas y recursos naturales es contraria al espíritu y a los principios de la Carta de las Naciones Unidas y entorpece el desarrollo de la cooperación internacional y la preservación de la paz.

32 Declaración sobre el Derecho al Desarrollo adoptado por la Asamblea General de las Naciones unidas el 4 de diciembre de 1986.

...Recordando además los acuerdos, convenciones, resoluciones, recomendaciones y demás instrumentos pertinentes de las Naciones Unidas y de sus organismos especializados relativos al desarrollo integral del ser humano y al progreso y desarrollo económicos y sociales de todos los pueblos, incluidos los instrumentos relativos a la descolonización, la prevención de discriminaciones, el respeto y la observancia de los derechos humanos y las libertades fundamentales, el mantenimiento de la paz y la 
La soberanía y el desarrollo se deben ejecutar en conjunto con la libre determinación y desarrollo económico, social y cultural teniendo la facultad a disponer de sus recursos naturales; vislumbrándose entonces las acciones de participación activa y democrática que han de ejercerse con el fin único de alcanzar y satisfacer el nivel de vida adecuado así en lo competente a la alimentación, salud, educación, vivienda, etc.; esta consideración permite satisfacer intereses propios y colectivos aprovechando adecuadamente sus recursos naturales ${ }^{33}$.

seguridad internacionales y el ulterior fomento de relaciones de amistad y cooperación entre los Estados de conformidad con la Carta.

Recordando el derecho de los pueblos a la libre determinación, en virtud del cual tienen derecho a determinar libremente su condición política y a realizar su desarrollo económico, social y cultural,

Recordando también el derecho de los pueblos a ejercer, con sujeción a las disposiciones pertinentes de ambos Pactos internacionales de derechos humanos, su soberanía plena y completa sobre todos sus recursos y riquezas naturales.

$\ldots$

Artículo 1

1. El derecho al desarrollo es un derecho humano inalienable en virtud del cual todo ser humano y todos los pueblos están facultados para participar en un desarrollo económico, social, cultural y político en el que puedan realizarse plenamente todos los derechos humanos y libertades fundamentales, a contribuir a ese desarrollo y a disfrutar de él.

2. El derecho humano al desarrollo implica también la plena realización del derecho de los pueblos a la libre determinación, que incluye, con sujeción a las disposiciones pertinentes de ambos Pactos internacionales de derechos humanos, el ejercicio de su derecho inalienable a la plena soberanía sobre todas sus riquezas y recursos naturales.

Artículo 2

1. La persona humana es el sujeto central del desarrollo y debe ser el participante activo y el beneficiario del derecho al desarrollo.

2. Todos los seres humanos tienen, individual y colectivamente, la responsabilidad del desarrollo, teniendo en cuenta la necesidad del pleno respeto de sus derechos humanos y libertades fundamentales, así como sus deberes para con la comunidad, único ámbito en que se puede asegurar la libre y plena realización del ser humano, y, por consiguiente, deben promover y proteger un orden político, social y económico apropiado para el desarrollo.

3. Los Estados tienen el derecho y el deber de formular políticas de desarrollo nacional adecuadas con el fin de mejorar constantemente el bienestar de la población entera y de todos los individuos sobre la base de su participación activa, libre y significativa en el desarrollo y en la equitativa distribución de los beneficios resultantes de éste.

33 Pacto Internacional de Derechos Económicos, Sociales y Culturales, Asamblea General de las Naciones Unidas Aprobado 16 de diciembre de 1966, dice lo siguiente:

Artículo 1.1. Todos los pueblos tienen el derecho de libre determinación. En virtud de este derecho establecen libremente su condición política y proveen asimismo a su desarrollo económico, social y cultural. 


\section{En la Declaración Universal sobre la Erradicación del Hambre y la Malnutrición ${ }^{34}$ establece la utilización de recursos marinos y aguas interiores como fuente de alimentos, debiendo preferirse su explotación para el consumo humano, se debe proteger el medio ambiente y realizar la cooperación internacional para la explotación racional de los recursos naturales.}

2. Para el logro de sus fines, todos los pueblos pueden disponer libremente de sus riquezas y recursos naturales, sin perjuicio de las obligaciones que derivan de la cooperación económica internacional basada en el principio del beneficio recíproco, así como del derecho internacional. En ningún caso podrá privarse a un pueblo de sus propios medios de subsistencia.

[...]

artículo 11.1. Los Estados Partes en el presente Pacto reconocen el derecho de toda persona a un nivel de vida adecuado para sí y su familia, incluso alimentación, vestido y vivienda adecuados, y a una mejora continua de las condiciones de existencia. Los Estados Partes tomarán medidas apropiadas para asegurar la efectividad de este derecho, reconociendo a este efecto la importancia esencial de la cooperación internacional fundada en el libre consentimiento.

2. Los Estados Partes en el presente Pacto, reconociendo el derecho fundamental de toda persona a estar protegida contra el hambre, adoptarán, individualmente y mediante la cooperación internacional, las medidas, incluidos los programas concretos, que se necesitan para:

a) Mejorar los métodos de producción, conservación y distribución de alimentos mediante la plena utilización de los conocimientos técnicos y científicos, la divulgación de principios sobre nutrición y el perfeccionamiento o la reforma de los regímenes agrarios de modo que se logren la explotación y la utilización más eficaces de las riquezas naturales.

$[\ldots]$

34 Declaración Universal sobre la Erradicación del Hambre y la Malnutrición. Asamblea General de las Naciones Unidas Aprobada el 16 de noviembre de 1974, se establece lo siguiente:

5. Hoy más que nunca, la utilización de los recursos marinos y de las aguas interiores cobra importancia, como nueva fuente de alimentos y de bienestar económico. Por lo tanto, se deben tomar medidas para promover una explotación racional de estos recursos, preferiblemente para consumo humano directo, con objeto de contribuir a satisfacer las necesidades de alimentos de todos los pueblos.

$\cdots$

9. A fin de asegurar una adecuada conservación de los recursos naturales que se utilizan o podrían utilizarse para la producción de alimentos, todos los países deben colaborar a fin de facilitar la conservación del medio ambiente, inclusive el medio marino.

10. Todos los países desarrollados, y aquellos que estén en condiciones de hacerlo, deberán colaborar técnica y financieramente con los países en desarrollo en sus esfuerzos por ampliar los recursos de tierra y agua para la producción agrícola, y para asegurar un rápido aumento de la disponibilidad, a costo razonable, de insumos agrícolas, como fertilizantes y otros productos químicos, semillas de alta calidad, crédito y tecnología. A este respecto, es también importante la cooperación entre los países en desarrollo. 
Es de carácter vital y de sobrevivencia el cuidado y gestión integral del agua ya que determina un uso racional, aunque lo racional impera en situaciones a veces irracionales; es decir, existe un mínimo de población "consciente" de la importancia del agua en su uso y distribución, el resto de la población realiza una mala gestión del recurso hídrico. Lo que ocasiona escenarios críticos en materia de salud, enfermedades, alimentos debido a que la contaminación del agua no permite su uso para la irrigación de los alimentos y en el caso de las enfermedades suscita reacciones secundarias, cuadros de epidemias o virus.

Continuando con el vínculo de situaciones emergentes en el desarrollo de una vida digna para el individuo, en el Pacto Internacional de Derechos Económicos, Sociales y Culturales, el derecho al agua se establece de manera indirecta, al acordarse de que los Estados partes, reconocen en los artículos 11 y 12, el derecho de las personas a la alimentación, a una adecuada nutrición, protección contra el hambre, y a la salud ${ }^{35}$. Resulta concreto señalar que en

35 Pacto Internacional de Derechos Económicos, Sociales y Culturales, adoptado y abierto a la firma, ratificación y adhesión por la Asamblea General en su resolución 2200 A (XXI), de 16 de diciembre de 1966. Entrada en vigor: 3 de enero de 1976, de conformidad con el artículo 27.

Artículo 11. 1. Los Estados Partes en el presente Pacto reconocen el derecho de toda persona a un nivel de vida adecuado para sí y su familia, incluso alimentación, vestido y vivienda adecuados, y a una mejora continua de las condiciones de existencia. Los Estados Partes tomarán medidas apropiadas para asegurar la efectividad de este derecho, reconociendo a este efecto la importancia esencial de la cooperación internacional fundada en el libre consentimiento.

2. Los Estados Partes en el presente Pacto, reconociendo el derecho fundamental de toda persona a estar protegida contra el hambre, adoptarán, individualmente y mediante la cooperación internacional, las medidas, incluidos los programas concretos, que se necesitan para:

a) Mejorar los métodos de producción, conservación y distribución de alimentos mediante la plena utilización de los conocimientos técnicos y científicos, la divulgación de principios sobre nutrición y el perfeccionamiento o la reforma de los regímenes agrarios de modo que se logren la explotación y la utilización más eficaces de las riquezas naturales;

b) Asegurar una distribución equitativa de los alimentos mundiales en relación con las necesidades, teniendo en cuenta los problemas que se plantean tanto a los países que importan productos alimenticios como a los que los exportan.

Artículo 12. 1. Los Estados Partes en el presente Pacto reconocen el derecho de toda persona al disfrute del más alto nivel posible de salud física y mental.

2. Entre las medidas que deberán adoptar los Estados Partes en el Pacto a fin de asegurar la plena efectividad de este derecho, figurarán las necesarias para: 
relación al desarrollo de la persona en la sociedad se debe contemplar el acceso a los derechos de los artículos antes citados.

La Observación general número 15, al citado Pacto Internacional, artículos 11 y $12^{36}$ reconoce que el agua es un recurso limitado y un bien público fundamental para la vida y la salud. Observación General número 15 "2. El derecho humano al agua es el derecho de todos a disponer de agua suficiente, salubre, aceptable, accesible y asequible para el uso personal y doméstico.

En estas observaciones se declara un estado de alerta o emergente al momento de manifestar el límite de un recurso natural que se consideraba ilimitado, al mismo tiempo se establece como un bien público con el único objeto de satisfacer y cubrir las necesidades básicas inherentes al recurso hídrico.

Sin duda alguna existe un costo por su procesamiento, sin embargo, el aludirlo como un elemento fundamental establece las directrices de cambio de acciones dirigidas a la prevención, tratamiento y soluciones de todas aquellas situaciones vulneradas que se encuentren, dentro de los parámetros de lo salubre, aceptable, accesible y asequible para el uso personal y doméstico.

a) La reducción de la mortinatalidad y de la mortalidad infantil, y el sano desarrollo de los niños;

b) El mejoramiento en todos sus aspectos de la higiene del trabajo y del medio ambiente;

c) La prevención y el tratamiento de las enfermedades epidémicas, endémicas, profesionales y de otra índole, y la lucha contra ellas;

d) La creación de condiciones que aseguren a todos asistencia médica y servicios médicos en caso de enfermedad.

36 Observación General número 15, del Derecho al Agua, artículo 11 y 12 del Pacto Internacional de Derechos Económicos, Sociales y Culturales, $29^{\circ}$ período de sesiones 2002 , numerales siguientes:

1. El agua es un recurso natural limitado y un bien público fundamental para la vida y la salud. El derecho humano al agua es indispensable para vivir dignamente y es condición previa para la realización de otros derechos humanos. El Comité ha constatado constantemente una denegación muy generalizada del derecho al agua, tanto en los países en desarrollo como en los países desarrollados.

[...]

3. En el párrafo 1 del artículo 11 del Pacto se enumeran una serie de derechos que dimanan del derecho a un nivel de vida adecuado, "incluso alimentación, vestido y vivienda adecuados", y son indispensables para su realización. El uso de la palabra "incluso" indica que esta enumeración de derechos no pretendía ser exhaustiva. El derecho al agua se encuadra claramente en la categoría de las garantías indispensables para asegurar un nivel de vida adecuado, en particular porque es una de las condiciones fundamentales para la supervivencia. 


\section{Instrumentos internacionales regionales interamericanos}

En relación a la protección del derecho al agua, se ha reconocido en dos instrumentos internacionales, el derecho a toda persona a tener uso y acceso al recurso hídrico; la primera en la Declaración Americana de los Derechos y Deberes del Hombre y el segundo en el Protocolo Adicional a la Convención Americana sobre Derechos Humanos en materia de Derechos Económicos, Sociales y Culturales "Protocolo de San Salvador."

En la Declaración Americana, se reconoce el derecho al agua de manera implícita en el derecho a la alimentación y como obligación de los padres de cumplir con dicho deber con sus hijos y viceversa cuando los padres lo necesiten ${ }^{37}$.

Se dispone entonces a considerar el cumplimiento de alimentos en términos de abastecer al ser humano con comestibles producidos por el propio individuo, pero dicho alimento demanda del agua para tener los nutrientes y ser un producto consumible; ejemplo de ello es el proceso de riego que abastece a grandes áreas de producción ${ }^{38}$;

37 Declaración Americana de los Derechos y Deberes del Hombre, Asamblea General de la Organización de los Estados Americanos Aprobada el 2 de junio de 1948, se estipula lo siguiente:

Capítulo I Derechos. Artículo 11. Toda persona tiene derecho a que su salud sea preservada por medidas sanitarias y sociales, relativas a la alimentación, el vestido, la vivienda y la asistencia médica, correspondientes al nivel que permitan los recursos públicos y los de la comunidad.

Capítulo II Deberes. Artículo 30. Toda persona tiene el deber de asistir, alimentar, educar y amparar a sus hijos menores de edad, y los hijos tienen el deber de honrar siempre a sus padres y el de asistirlos, alimentarlos y ampararlos cuando éstos lo necesiten.

38 Esta acción es lo que se denomina como huella hídrica, por ejemplo: Cuesta alrededor de 21,000 litros de agua producir $1 \mathrm{~kg}$ de café tostado. Para una taza normal de café, se requieren 7 gramos de café tostado, por lo que una taza de café cuesta 140 litros de agua. Suponiendo que una taza normal de café tenga $125 \mathrm{ml}$, necesitamos entonces más de 1,100 gotas de agua para producir una gota de café. Beber té en vez de café se ahorraría una gran cantidad de agua. Para una taza de té estándar de $250 \mathrm{ml}$ se requieren 30 litros de agua. En el caso la carne de res; una vaca (para producción de carne) es de 3, 100,000 litros. En un sistema de producción industrial de carne, toma en promedio tres años antes de que el animal sea sacrificado para producir unos $200 \mathrm{~kg}$ de carne deshuesada. El animal consume cerca de 1,300 kg de granos (trigo, avena, cebada, maíz, chicharos secos, harina de soya y otros granos pequeños), 7,200 $\mathrm{kg}$ de forrajes (pastos, heno seco, ensilaje y otros), $24 \mathrm{~m} 3$ de agua para beber y $7 \mathrm{~m} 3$ de agua para mantenimiento. Esto significa que, para producir un kilogramo de carne de vacuno deshuesada, utilizamos alrededor de $6.5 \mathrm{~kg}$ de grano, $36 \mathrm{~kg}$ de forrajes y 155 litros de agua (sólo para consumo y mantenimiento. La sola producción de los granos necesarios como alimento requiere de 15,300 litros de agua en promedio. 
así como el proceso de preparación y empaque ${ }^{39}$ de todos aquellos alimentos necesarios de grandes cantidades de litro de agua.

El Protocolo Adicional a la Convención de manera sobrentendida reconoce el derecho a la salud, nutrición y distribución de alimentos ${ }^{40}$. A partir de toda inversión económica, social y política con fortaleza en el aspecto de salud que infiera de forma transversal el interés público, el bienestar físico, mental y social.

39 Esta acción se le conoce como agua virtual, es toda el agua que se necesita para producir, empacar y transportar los bienes y servicios que consumimos. Se dice que es virtual porque no está presente en los productos finales. La Secretaría de Medio Ambiente y Recursos Naturales SEMARNAT, señala que del agua que usamos a diario sólo vemos, tocamos y sentimos aproximadamente el cinco por ciento. Los noventa y cinco restantes es agua virtual y está en nuestros alimentos, ropa, calzado, aparatos electrónicos y todos los productos que usamos en la vida diaria. Ejemplo de la presencia del agua virtual es el microchip de dos gramos para lo cual se requiere de treinta y dos litros de agua; una camiseta de algodón con un peso de $250 \mathrm{gr}$. requiere de dos mil litros de agua.

40 Protocolo Adicional a la Convención Americana sobre Derechos Humanos en materia de Derechos Económicos, Sociales y Culturales "Protocolo de San Salvador", Asamblea General de la Organización de los Estados Americanos Adoptado el 17 de noviembre de 1988.

Artículo 10 Derecho a la Salud. 1. Toda persona tiene derecho a la salud, entendida como el disfrute del más alto nivel de bienestar físico, mental y social.

2. Con el fin de hacer efectivo el derecho a la salud los Estados partes se comprometen a reconocer la salud como un bien público y particularmente a adoptar las siguientes medidas para garantizar este derecho:

a. La atención primaria de la salud, entendiendo como tal la asistencia sanitaria esencial puesta al alcance de todos los individuos y familiares de la comunidad;

b. La extensión de los beneficios de los servicios de salud a todos los individuos sujetos a la jurisdicción del Estado;

c. La total inmunización contra las principales enfermedades infecciosas;

d. La prevención y el tratamiento de las enfermedades endémicas, profesionales y de otra índole;

e. La educación de la población sobre la prevención y tratamiento de los problemas de salud, y

f. La satisfacción de las necesidades de salud de los grupos de más alto riesgo y que por sus condiciones de pobreza sean más vulnerables.

Artículo 11 Derecho a un Medio Ambiente Sano. 1. Toda persona tiene derecho a vivir en un medio ambiente sano y a contar con servicios públicos básicos.

2. Los Estados partes promoverán la protección, preservación y mejoramiento del medio ambiente.

Artículo 12 Derecho a la Alimentación. 1. Toda persona tiene derecho a una nutrición adecuada que le asegure la posibilidad de gozar del más alto nivel de desarrollo físico, emocional e intelectual.

2. Con el objeto de hacer efectivo este derecho y a erradicar la desnutrición, los Estados partes se comprometen a perfeccionar los métodos de producción, aprovisionamiento y distribución de alimentos, para lo cual se comprometen a promover una mayor cooperación internacional en apoyo de las políticas nacionales sobre la materia. 


\section{Instrumentos internacionales del derecho al agua de los grupos vulnerables}

Los instrumentos internacionales en el ámbito universal, establecen diversas reglas que pretenden el acceso al derecho humano al agua. El acceso al derecho al agua se garantiza a diversos grupos vulnerables como son a los 1) los trabajadores y 2) sus viviendas, 3) las mujeres, 4) los menores, 5) los discapacitados, 6) los internos, 7) los menores privados de su libertad, 8) las personas de la tercera edad, 9) los desplazados, 10) los indígenas y 11) toda persona en los términos siguientes:

1) Los Trabajadores ${ }^{41}$ tienen derecho a servicios de salud en el trabajo, de manera independiente de las obligaciones de sus empleadores, tienen el derecho a un ambiente de trabajo que no afecte la salud y a instalaciones sanitarias. Es importante destacar la importancia del acceso al agua para tener una salud adecuada. 2) Las viviendas de los trabajadores ${ }^{42}$ se prevé en las Recomendaciones del Tratado de la Organización Internacional del Trabajo OIT número 115, que deben tener suficiente agua potable, instalaciones sanitarias y adecuado alcantarillado.

41 La Convención de la OIT N 161 de 1985 sobre Servicios de Salud en el Trabajo señala en su Artículo 5, lo siguiente:

Sin perjuicio de la responsabilidad de cada empleador respecto de la salud y la seguridad de los trabajadores a quienes emplea, los servicios de salud en el trabajo deberán asegurar las funciones siguientes...:

(a) $[\ldots]$

(b) vigilancia de los factores del medio ambiente de trabajo y de las prácticas de trabajo que puedan afectar a la salud de los trabajadores, incluidos las instalaciones sanitarias.

42 En la Recomendación de la OIT N 115 de 1961 sobre la Vivienda de los Trabajadores Sugerencias acerca de los métodos de aplicación...

7. Las normas de vivienda mencionadas en el párrafo 19 de los Principios generales deberían referirse, en particular:

(b) al abastecimiento de agua potable dentro de la vivienda del trabajador, en cantidad suficiente para poder cubrir todas las necesidades personales y domésticas;

(c) a los sistemas adecuados de alcantarillado y de evacuación de basuras; ...

8. Cuando la vivienda destinada a trabajadores solteros o a trabajadores separados de sus familias sea colectiva, la autoridad competente debería establecer ciertas normas de habitación que dispongan, como mínimo: ...

(c) que haya suficiente abastecimiento de agua potable;

(d) que existan adecuadas instalaciones sanitarias y de desagüe; ... 
3) La mujer ${ }^{43}$ tiene el derecho de que los Estados Partes de manera obligada adopten las medidas apropiadas para eliminar la discriminación contra la mujer en las zonas rurales de manera que puedan gozar de vida adecuadas como el abastecimiento de agua. En este sentido, el Comité para la Eliminación de la Discriminación contra las Mujeres consideró que este artículo obliga a los Estados parte a tomar todas las medidas apropiadas para asegurar condiciones de vida en relación con el agua y el saneamiento cruciales para la prevención de enfermedades y la promoción de una buena asistencia sanitaria ${ }^{44}$.

4) Los niños ${ }^{45}$ tienen la protección del Estado de garantizar el más alto nivel posible de salud, el cual requiere de manera "crucial para la prevención de enfermedades" del acceso al agua suficiente y salubre. La misma Declaración de los Derechos del Niño, principio $4^{46}$ reconoce que "el derecho de los niños a la

43 En la Convención sobre la Eliminación de todas las Formas de Discriminación contra la Mujer (CEFDM), Asamblea General de las Naciones Unidas Aprobada el 18 de diciembre de 1979, en su Artículo 14 (2) señala lo siguiente:

Los Estados Partes adoptarán todas las medidas apropiadas para eliminar la discriminación contra la mujer en las zonas rurales a fin de asegurar, en condiciones de igualdad entre hombres y mujeres, su participación en el desarrollo rural y en sus beneficios, y en particular le asegurarán el derecho a:

(h) Gozar de condiciones de vida adecuadas, particularmente en las esferas de la vivienda, los servicios sanitarios, la electricidad y el abastecimiento de agua, el transporte y las comunicaciones.

44 Comité para la Eliminación de la Discriminación contra la Mujer, recomendación general $\mathrm{N}^{\circ} 24$ (1999) sobre el artículo 12 de la Convención (la mujer y la salud), párrafo 28).

45 Convención sobre los Derechos del Niño (CDN), Asamblea General de las Naciones Unidas, aprobada el 20 de noviembre de 1989, establece lo siguiente:

Artículo 24. 1. Los Estados Partes reconocen el derecho del niño al disfrute del más alto nivel posible de salud y a servicios para el tratamiento de las enfermedades y la rehabilitación de la salud...

2. Los Estados Partes asegurarán la plena aplicación de este derecho y, en particular, adoptarán las medidas apropiadas para:

(c) Combatir las enfermedades y la malnutrición en el marco de la atención primaria de la salud mediante, entre otras cosas, (...) el suministro de alimentos nutritivos adecuados y agua potable salubre (...)

46 Declaración de los Derechos del Niño Asamblea General de las Naciones Unidas, aprobada el 20 de noviembre de 1959, Principio 4:

El niño debe gozar de los beneficios de la seguridad social. Tendrá derecho a crecer y desarrollarse en buena salud; con este fin deberán proporcionarse, tanto a él como a su madre, cuidados especiales, incluso atención prenatal y postnatal. El niño tendrá derecho 
salud el bienestar, y en especial la alimentación". El Comité de los Derechos del Niño de Naciones Unidas enfatiza que de acuerdo con el artículo $24^{47}$ citado los Estados tienen la responsabilidad de garantizar el acceso a agua potable salubre y que este acceso es particularmente esencial para la salud de los niños pequeños. 5) Los discapacitados ${ }^{48}$ tienen el derecho al trato de igualdad como es el caso del acceso en condiciones de igualdad de las personas con discapacidad a servicios de agua potable y su acceso a servicios, dispositivos y asistencia de otra índole a precios asequibles para atender las necesidades relacionadas con su discapacidad.

6) Los internos y/o reclusos ${ }^{49}$ tienen derecho al acceso al agua para aseo personal, salud y limpieza, así como del acceso al agua potable en el momento que lo requiera.

7) Los menores privados de su libertad ${ }^{50}$ tienen derecho a que las instalaciones en materia de infraestructura donde se hayan, satisfagan las necesidades físicas y en forma aseada.

a disfrutar de alimentación, vivienda, recreo y servicios médicos adecuados.

47 Comité de los Derechos del Niño, Observación General N 7 (2006) sobre la realización de los derechos del niño en la primera infancia, Párrafo 27.

48 Convención sobre los Derechos de las Personas con Discapacidad (CDPD), Artículo 28 Nivel de vida adecuado y protección social que dice así:

1.- $[\ldots]$

2. Los Estados Partes reconocen el derecho de las personas con discapacidad a la protección social y a gozar de ese derecho sin discriminación por motivos de discapacidad, y adoptarán las medidas pertinentes para proteger y promover el ejercicio de ese derecho, entre ellas:

(a) Asegurar el acceso en condiciones de igualdad de las personas con discapacidad a servicios de agua potable y su acceso a servicios, dispositivos y asistencia de otra índole adecuados a precios asequibles para atender las necesidades relacionadas con su discapacidad.

49 En las Reglas Mínimas para el Tratamiento de los Reclusos, numeral 15, dice lo siguiente: 15. Se exigirá de los reclusos, aseo personal y a tal efecto dispondrán de agua y de los artículos de aseo indispensables para su salud y limpieza.

$[\ldots]$

20. (2) Todo recluso deberá tener la posibilidad de proveerse de agua potable cuando la necesite.

50 En las Reglas de Naciones Unidas para la protección de menores privados de libertad, Artículos 34 y 37, que señalan lo siguiente:

Artículo 34. Las instalaciones sanitarias deberán ser de un nivel adecuado y estar situadas de modo que el menor pueda satisfacer sus necesidades físicas en la intimidad y en forma aseada y decente. 
8) Las personas de la tercera edad y sus familias ${ }^{51}$ tienen derecho al acceso al agua suficiente.

9) Los desplazados internos ${ }^{52}$ tienen derecho a una vida digna, de manera que comprende el acceso al agua potable y a servicios de saneamiento indispensables.

10) Los indígenas. La relación de los pueblos indígenas con el agua está estrechamente relacionada no solamente con el acceso al agua, sino a sus tradiciones, usos y costumbres, creencias religiosas, formas de alimentación, conservación del medio ambiente, uso equilibrado del medio, salud, alimentación, cultura entre otros derechos universales no solamente como individuos sino en la mayoría de los casos como comunidades o pueblos indígenas.

La relación entre el recurso hídrico y grupos vulnerables ${ }^{53}$ es estrecha al tener el compromiso en mayor grado el Estado en conjunto con la sociedad de garantizar el acceso al agua como derecho, implica capacitación para participar en los procesos de toma de decisiones;

Artículo 37. Todos los centros de detención deben garantizar que todo menor disponga de una alimentación adecuadamente preparada... Todo menor deberá disponer en todo momento de agua limpia y potable.

51 En los Principios de las Naciones Unidas en favor de las Personas de Edad, se resalta en el numeral 1, lo siguiente:

1. Las personas de edad deberán tener acceso a alimentación, agua, vivienda, vestimenta y atención de salud adecuados, mediante ingresos, apoyo de sus familias y de la comunidad y su propia autosuficiencia.

52 Los Principios rectores de los de los desplazamientos internos, Comisión de los Derechos Humanos de las Naciones Unidas, aprobado el 11 de febrero de 1998, en el Principio 18, señala lo siguiente:

1. Los desplazados internos tienen derecho a un nivel de vida adecuado.

2. Cualesquiera que sean las circunstancias, las autoridades competentes suministrarán a los desplazados internos, como mínimo y sin discriminación, y se cerciorarán de que pueden recibir en condiciones de seguridad:

(a) alimentos indispensables y agua potable; ...

(d) servicios médicos y de saneamiento indispensables.

3. Se tratará en especial de garantizar que las mujeres participen plenamente en la planificación y distribución de estos suministros básicos.

53 Oficina de Naciones Unidas de apoyo al Decenio Internacional para la Acción "El agua fuente de vida" 2005-2015. El derecho humano al agua y saneamiento, Programa de ONU-Agua para la promoción y la comunicación en el marco del Decenio, España, 2010. 
asimismo legitimar la acción de no discriminación a cualquier persona que pertenezca a un grupo vulnerable.

Ante el inminente proceso de globalización prevalecen situaciones complejas que afectan a grupos vulnerables, sociedad civil y diversos ecosistemas, entre otros; aconteciendo de forma recurrente en la vida diaria de las personas dichas conductas que llegan a ser reflejo de una cultura y en dado caso empeorando al momento de aceptar esos procesos o ciclos de vida no aptos como lo es la contaminación de recursos naturales, explotación del agua, contaminación de afluentes de ríos con desechos tóxicos, entre otros.

Es importante resaltar que en relación a grupos vulnerables no existen instrumentos internacionales específicos que protejan el derecho al agua de forma expresa a los pueblos indígenas, sino de manera indirecta, al proteger, los derechos a la propiedad, protección ambiental, subsistencia, preservación cultural, discriminación racial y autodeterminación; sin embargo, existen instrumentos dispersos y generales en los últimos cincuenta años que se han generado respecto a los derechos humanos aplicable a los derechos de los pueblos indígenas, como lo siguiente ${ }^{54}$ :

1948 la Asamblea General de la Organización de los Estados Americanos tomó el primer paso al aceptar el artículo 39 de la Carta Interamericana de Garantías Sociales; la cual establece la protección de vidas y propiedades defendiéndola de la exterminación, opresión y explotación. Así también la OIT en 1989 reconoce el poder de los pueblos indígenas para asumir instituciones propias, formas de vida que adquiere identidad propia dentro del marco de los Estado en que viven.

El Pacto Internacional de Derechos Económicos, Sociales y Culturales ${ }^{55}$, estipula que en "ningún caso podrá privarse a un pueblo de sus propios medios de subsistencia”.

54 Getches, H, David, Derechos de los Pueblos indigenas al agua y normas internacionales, pp. 1 y 2. Internet www.cepal.org.

55 Pacto Internacional de Derechos Económicos, Sociales y Culturales, Adoptado y abierto a la firma, ratificación y adhesión por la Asamblea General en su resolución 2200 A (XXI), de 16 de diciembre de 1966. Entrada en vigor: 3 de enero de 1976, de conformidad con el artículo 27.

Artículo 1.- 1. Todos los pueblos tienen el derecho de libre determinación. En virtud de este derecho establecen libremente su condición política y proveen asimismo a su desarrollo económico, social y cultural.

2. Para el logro de sus fines, todos los pueblos pueden disponer libremente de sus riquezas 
En las Observaciones Generales número 12 al artículo 11 del Pacto Internacional de Derechos Económicos, Sociales y Culturales, del Derecho a la alimentación adecuada, la vulnerabilidad del derecho a la alimentación a los pueblos indígenas que en ocasiones se les impide el acceso físico a sus tierras ancestrales ${ }^{56}$.

En la Observación número 14, del mismo Pacto, establece el disfrute del más alto nivel posible de salud un medio es la higiene ambiental ${ }^{57}$; el derecho al acceso al agua a los pueblos indígenas es claro, en la Observación General número $15^{58}$ dispone en el artículo 1. Numeral 2, del Pacto Internacional de referencia, el derecho de los pueblos a no privársele de sus medios propios de subsistencia, el Comité de Derechos Económicos, Sociales y Culturales, dice lo siguiente:

7.

$[\ldots]$

Tomando nota de la obligación establecida en el párrafo 2 del artículo 1 del Pacto, que dispone que no podrá privarse a un pueblo "de sus propios medios

y recursos naturales, sin perjuicio de las obligaciones que derivan de la cooperación económica internacional basada en el principio de beneficio recíproco, así como del derecho internacional. En ningún caso podrá privarse a un pueblo de sus propios medios de subsistencia.

56 Observaciones Generales número 12 al artículo 11 del Pacto Internacional de Derechos Económicos, Sociales y Culturales, numeral 13, del derecho a la alimentación, dice lo siguiente: 13.

$[\ldots]$

La accesibilidad física implica que la alimentación adecuada debe ser accesible a todos, incluidos los individuos físicamente vulnerables...Son especialmente vulnerables muchos grupos de pueblos indígenas cuyo acceso a las tierras ancestrales puede verse amenazado."

57 Observaciones Generales número 14 al artículo 12 del Pacto Internacional de Derechos Económicos, Sociales y Culturales, numeral 13, del derecho al disfrute del más alto nivel posible de salud, dice lo siguiente:

27.

[...]

A este respecto, el Comité considera que las actividades relacionadas con el desarrollo que inducen al desplazamiento de poblaciones indígenas, contra su voluntad, de sus territorios y entornos tradicionales, con la consiguiente pérdida por esas poblaciones de sus recursos alimenticios y la ruptura de su relación simbiótica con la tierra, ejercen un efecto perjudicial sobre a salud de esas poblaciones.

58 Observaciones Generales número 15 a los artículos 11 y 12 del Pacto Internacional de Derechos Económicos, Sociales y Culturales, del Derecho al Agua, $29^{\circ}$ período de sesiones, 2002. numeral 7 . 
Dimensiones sociales y económicas del uso del recurso hídrico

de subsistencia”, los Estados Partes deberían garantizar un acceso suficiente al agua para la agricultura de subsistencia y para asegurar la de subsistencia de los pueblos indígenas.

11) Toda persona tiene derecho al acceso al agua potable y saneamiento adecuado $^{59}$.

Toda persona que corresponda a un grupo o sector vulnerable tiene mayor necesidad de requerir y tener la prevención de ser atendido a partir de los principios de equidad.

\section{Normas de origen interno}

La fundamentación del derecho al agua en la Constitución Política de los Estados Unidos Mexicanos, se establece en los artículos 4, párrafo 5; 115, fracción III, inciso a); y 122, apartado C, siguientes:

Artículo 4.

[...]

Toda persona tiene derecho al acceso, disposición y saneamiento de agua para consumo personal y doméstico en forma suficiente, salubre, aceptable y asequible. El Estado garantizará este derecho y la ley definirá las bases, apoyos y modalidades para el acceso y uso equitativo y sustentable de los recursos hídricos, estableciendo la participación de la Federación, las entidades federativas y los municipios, así como la participación de la ciudadanía para la consecución de dichos fines.

Artículo 115

III. Los Municipios tendrán a su cargo las funciones y servicios públicos siguientes:

a) Agua potable, drenaje, alcantarillado, tratamiento y disposición de sus aguas residuales...

59 En las Directrices voluntarias en apoyo de la realización progresiva del derecho a una alimentación adecuada en el contexto de la seguridad alimentaria nacional (FAO), en sus numerales siguientes:

3.6 En sus estrategias de reducción de la pobreza, los Estados también deberían conceder prioridad a la prestación de servicios básicos a los más pobres y a la inversión en los recursos humanos, garantizando el acceso universal a ... el agua potable, un saneamiento adecuado ...

$[\ldots]$

8.1 Los Estados deberían facilitar el acceso a los recursos y su utilización de manera sostenible, no discriminatoria y segura de acuerdo con su legislación nacional y con el derecho internacional y deberían proteger los bienes que son importantes para la subsistencia de la población. Los Estados deberían respetar y proteger los derechos individuales relativos a los recursos como la tierra, el agua, ... 
Artículo 122

C. La Federación, la Ciudad de México, así como sus demarcaciones territoriales, y los Estados y Municipios conurbados en la Zona Metropolitana, establecerán mecanismos de coordinación administrativa en materia de planeación del desarrollo y ejecución de acciones regionales para la prestación de servicios públicos, en términos de la ley que emita el Congreso de la Unión.

Para la eficaz coordinación a que se refiere el párrafo anterior, dicha ley establecerá las bases para la organización y funcionamiento del Consejo de Desarrollo Metropolitano, al que corresponderá acordar las acciones en materia de asentamientos humanos; protección al ambiente; preservación y restauración del equilibrio ecológico; transporte; tránsito; agua potable y drenaje; recolección, tratamiento y disposición de desechos sólidos, y seguridad pública.

La pretensión de la Ley encara una serie de acciones que deben ir de la mano con políticas públicas que atiendan cada uno de las presunciones de forma sistemática y en conjunto entre dependencias municipales, estatales y federales; procurando la atención a las demandas y necesidades de la población de forma directa, pero considerando de forma sustentable e integral todos aquellos objetivos globales e instrumentos internacionales enmarcados en el derecho al agua como bien vital.

Por lo anterior, se resalta que todavía existe una brecha crucial en lo que se establece en las normas a lo que se hace de acuerdo a las funciones de las instituciones encargadas de abastecer y otorgar acceso al derecho al agua, por otra parte la poca o nula participación de la población crea acciones de irracionalidad en el uso y gestión del agua; motivo por el cual la sinergia de estos dos aspectos otorga al concepto de violación del derecho humano al agua, los siguientes aspectos o elementos:

A. Acción u omisión por medio de la cual se impide el acceso, disposición y saneamiento de agua para consumo personal y doméstico.

B. Realizada directa o indirectamente por una autoridad o servidor público.

C. Sin fundamentación legal, causando perjuicio a cualquier persona. 


\section{Obligaciones de los estados de garantizar el derecho al agua}

La experta independiente de la ONU, Carina de Albuquerque presentó el Informe sobre la Obligaciones de derechos humanos relacionadas con el acceso al agua potable y el saneamiento ${ }^{60}$ a la Asamblea General de la Naciones Unidas en donde expone las obligaciones que tienen los Estados de garantizar el acceso al derecho al agua, proponiendo las siguientes siete recomendaciones:

1. El acceso universal al agua debe ser progresivo, por lo que los Estados deben adaptar, ajustar y contextualizar los Objetivos de Desarrollo del Milenio, ahora Objetivos de Desarrollo Sostenible en el plano nacional, debiendo los Estados adoptar medidas deliberadas, concretas y selectivas para realizar progresivamente el derecho al agua y saneamiento. Para lograr el cumplimiento de los Objetivos y respeto del derecho al agua, los Estados deben elaborar planes y estrategias nacionales respaldados al más alto nivel político con estrategias de reducción de la pobreza y los marcos de gastos nacionales para asegurar su funcionamiento, sostenibilidad y exhaustividad. Se trata de abordar la situación compleja mediante la transversalidad y actores implicados además de integrar las alternativas para el acceso y garantía del derecho. El saneamiento y el agua se deben considerar prioritarios y reflejarse en las asignaciones de los presupuestos del Estado. Los Estados deben eliminar la discriminación, las desigualdades y la exclusión sistemática de los grupos vulnerables.

2. Cooperación y asistencia internacional. Se requiere planificar de conformidad con las normas y principios de derechos humanos, incluidos los derechos al agua y el saneamiento, así como las obligaciones de derechos humanos relativas a la no discriminación. La asistencia oficial internacional para el desarrollo destinado al sector del agua y el saneamiento debe

60 Informe de la Experta Independiente, Carina de Albuquerque, sobre cuestión de las obligaciones de derechos humanos relacionadas con el acceso al agua potable y saneamiento, ONU, Asamblea General, A/65/254 del 6 de agosto de 2010. Sexagésimo quinto periodo de sesiones. 
ser más selectiva para que llegue principalmente a quienes más la necesitan.

3. Armonización de las metas y los indicadores con los derechos humanos. La formulación de objetivos, metas e indicadores mundiales nuevos o revisados y su adaptación a nivel nacional debe regirse por las normas y los principios de derechos humanos, incluido el contenido normativo de los derechos al agua y el saneamiento, así como por los criterios de la no discriminación, la participación y la rendición de cuentas. En particular, los futuros indicadores deben reflejar los criterios de disponibilidad, seguridad, aceptabilidad, accesibilidad (incluida la fiabilidad) y asequibilidad de conformidad con las normas de derechos humanos. En la recopilación es necesario desglosar los datos relativos a los progresos en función de los diferentes motivos de discriminación: de género y de riqueza.

4. Más allá de los promedios: no discriminación. Los Estados en donde existan regiones con acceso prácticamente universal al agua y el saneamiento no puede ser motivo de complacencia y no deben pasar por alto los focos persistentes de pobreza, sino que deben seguir centrándose en la lucha contra la discriminación y la exclusión sistemáticas.

5. Participación y empoderamiento para obtener información sobre el agua y saneamiento. Los Estados deben promover procesos participativos y empoderar a las personas para que participen activamente en procesos de adopción de decisiones, incluida la utilización de la asistencia para el desarrollo, entre otras cosas venciendo obstáculos como el alto nivel de analfabetismo, las limitaciones relacionadas con el idioma y los obstáculos culturales y físicos. Para lograr una participación significativa es preciso asegurar la plena transparencia. Todas las personas deben tener un acceso pleno y equitativo a la información sobre el agua y el saneamiento, así como a los planes, las políticas y los programas conexos, incluida la utilización de la asistencia para el desarrollo.

6. Enfoques intersectoriales y examen de las causas fundamentales. Los Estados deben afrontar la cuestión del 
agua y el saneamiento de forma global incluyendo las causas subyacentes de la falta de acceso. A estos efectos, son esenciales los enfoques intersectoriales, entre ellos, la integración del saneamiento y el agua en las iniciativas de protección social.

7. Fortalecimiento de la rendición de cuentas a nivel nacional y mundial. Los Estados deben establecer mecanismos accesibles, asequibles, oportunos y efectivos de rendición de cuentas. Es preciso que los mecanismos de rendición de cuentas judiciales y de otra índole estén al alcance de todos a fin de reforzar la rendición de cuentas para la consecución de los Objetivos de Desarrollo Sostenible. Deben realizarse evaluaciones más sistemáticas de las consecuencias para los derechos humanos.

Con el objeto de una mayor comprensión respecto a las obligaciones de los Estados de garantizar el derecho al agua, se presenta el siguiente gráfico en donde involucra al Estado con el individuo en un estado de corresponsabilidad en las obligaciones:

\section{Gráfico 2. Obligaciones del Estado en la garantía del derecho al agua}

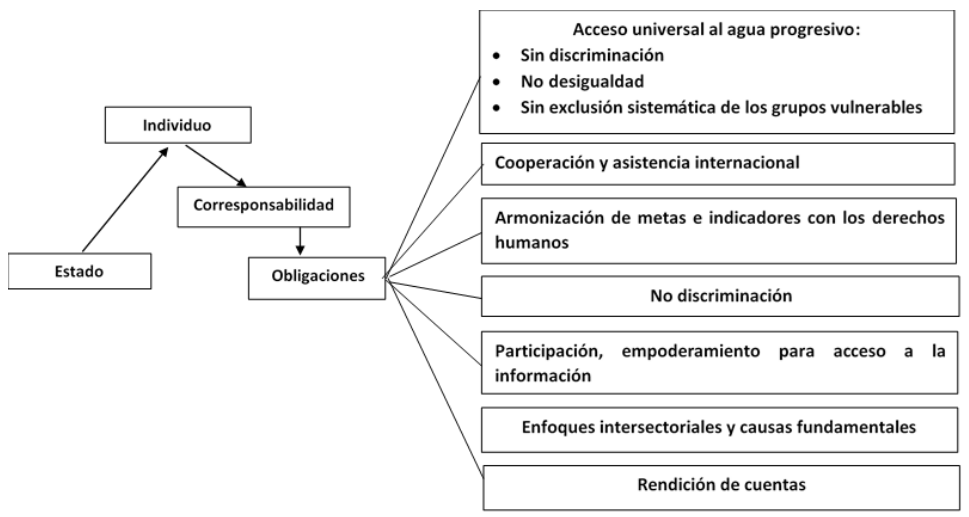

Fuente: Elaboración propia.

Estas obligaciones del Estado deben ejecutarse de forma integral, transparente, equitativa y funcional en un esquema de inclusión y participación social el cual legitime a los actores de la sociedad a 
través del empoderamiento para la toma de decisiones en consenso con el objeto de lograr el bien común y a su vez satisfacer las necesidades e intereses del bien individual.

\section{Buenas prácticas de acceso al agua y saneamiento}

La experta independiente de la ONU, Carina de Albuquerque presentó un Informe sobre la marcha de los trabajos de recopilación de buenas prácticas ${ }^{61}$ a la Asamblea General de la Naciones Unidas en donde expone cinco criterios normativos: disponibilidad, calidad y seguridad, aceptabilidad, accesibilidad y asequibilidad. Asimismo, expone cinco criterios comunes: no discriminación, participación, responsabilidad, repercusión y sostenibilidad.

1. Disponibilidad. El criterio establece que debe estar disponible de forma continua y en cantidad suficiente para satisfacer las necesidades de agua potable y de higiene personal, así como para otros usos personales y domésticos, como cocinar y preparar alimentos, o lavar vajilla y ropa ${ }^{62}$. La cantidad de agua no puede cuantificarse, varía de región en región, condiciones climáticas y condiciones de salud. Las buenas prácticas consisten en que se dé prioridad al uso del agua uso personal y básico, el uso de tecnologías para usar menos.

2. Calidad y seguridad. Existe un sector muy importante de la población mundial que consume el agua de mala calidad lo que afecta la salud y tiene consecuencias en la asistencia a la escuela y el trabajo. Se debe prever que no se contamine el agua evitando enfermedades de origen hídrico. La Guía para la calidad del agua potable la Organización Mundial de la Salud (OMS) define el agua potable como aquella que "no ocasiona ningún riesgo significativo para la salud cuando se consume durante toda una vida, teniendo en cuenta las diferentes vulnerabilidades que pueden presentar las personas

61 Informe de la Experta Independiente, Catarina de Albuquerque, sobre la marcha de los trabajos de recopilación de buenas prácticas, ONU, Asamblea General, A/HRC/15/31/Add. 1 del 1 de julio de 2010. Consejo de Derechos Humanos, $15^{\circ}$ período de sesiones.

62 Comité de Derechos Económicos, Sociales y Culturales, Observación general No 15, párr. 12 a). 
durante las etapas de su vida ${ }^{63}$. Las buenas prácticas son la elaboración de normas jurídicas que supervisen la calidad del agua y métodos higiénicos de almacenamiento de la misma.

3. Aceptabilidad. Las soluciones para el saneamiento y el abastecimiento de agua que son aceptables en un contexto dado difieren, por ejemplo, la higiene personal es una cuestión muy delicada en todas las culturas. Las buenas prácticas consisten en realizar consultas constantes para conocer su percepción de "aceptabilidad".

4. Accesibilidad. El derecho a la accesibilidad consiste en que las barreras que existan para obtener el agua, no afecten de manera que impida su acceso como la distancia. Se puede tener mucha agua, pero está muy lejos y requieren ocupar muchas horas para obtenerla. Por lo que sostiene el Informe que: "las instalaciones de saneamiento deben ser físicamente accesibles para todos en el interior, o en las inmediaciones de cada hogar, institución educativa o de salud, instituciones y lugares públicos y lugar de trabajo" (A/HRC/12/24, párrafo 75). Las buenas prácticas corresponden a casos de mejoramiento de acceso con instalaciones físicas a los discapacitados. Asimismo, la movilización de comunidades para garantizar la seguridad en las instalaciones de agua y saneamiento.

5. Asequibilidad. Consiste en tener acceso al agua, como el estar conectado a una red pública de distribución de agua de manera que el dinero que ocupen las personas para obtener el agua no se convierta en inasequibles. Las buenas prácticas es también el uso de microcréditos para la adquisición de conectarse en las redes de distribución, tarifas con subvenciones.

Estos criterios están reconocidos y establecidos en la norma de origen interno en el caso de México a partir de la Constitución Política, en la cual los refiere como derecho humano para acceso a toda persona. Parten del principio de equidad y distribución con características vitales para su uso, distribución y consumo humano.

63 Organización Mundial de la Salud, Guías para la calidad del agua potable, $3^{\text {a }}$ edición, Ginebra, 2008, pág. 11. 
Los criterios comunes son cinco:

1. La "no discriminación" en la distribución o acceso al agua o saneamiento, es importante tomar en consideración, el Comité de Derechos Económicos, Sociales y Culturales cataloga la discriminación como "toda distinción, exclusión, restricción o preferencia u otro trato diferente que directa o indirectamente se base en los motivos prohibidos de discriminación y que tenga por objeto o por resultado anular o menoscabar el reconocimiento, goce o ejercicio, en condiciones de igualdad, de los derechos reconocidos en el Pacto Internacional de Derechos Económicos, Sociales y Culturales ${ }^{64}$.

2. La "participación" de la población en algunos proyectos de distribución y acceso al agua y saneamiento es un elemento importante en el proceso de abastecimiento el cual está vinculado con los derechos de libertad activa, expresión, asociación, reunión, acceso a la información y transparencia.

3. Responsabilidad. Para hacerla efectiva los Estados deben establecer mecanismos que sean accesibles, no onerosos, rápidos y eficaces ${ }^{65}$. Debe velarse por el acceso a la justicia en términos prácticos, lo que significa que la población debe tener acceso físico y económico, incluso mediante sistemas de asistencia letrada, y debe proporcionarse información en las lenguas vernáculas. El Estado debe asegurarse de que las víctimas de las violaciones tengan derecho a una reparación adecuada, que puede consistir en restitución, indemnización, satisfacción o garantías de que no se repetirán los hechos ${ }^{66}$.

4. Repercusión ${ }^{67}$. Se refiere al examen de repercusiones de ciertas actividades que pueden afectar la disponibilidad

64 Comité de Derechos Económicos, Sociales y Culturales, Observación general N. ${ }^{\circ} 20$ (2009) sobre la no discriminación y los derechos económicos, sociales y culturales, párrafo 7. 65 Comité de Derechos Económicos, Sociales y Culturales, Observación general N. 9 (1998) sobre la aplicación interna del Pacto, párr. 9.

66 Comité de Derechos Económicos, Sociales y Culturales, Observación general N. ํ 15, párr. 55

67 Comité de Derechos Económicos, Sociales y Culturales, Observación general N. ${ }^{\circ}$ 15, Los Estados partes deben adoptar estrategias y programas amplios integrados que dispongan de agua suficiente y salubre, inciso e. 
del agua y en las cuencas hidrográficas de los ecosistemas naturales, como los cambios climáticos, la desertificación, y la creciente salinidad del suelo, la deforestación y la pérdida de biodiversidad.

5. Sostenibilidad. Entraña el concepto de disponibilidad y accesibilidad a largo plazo.

Estas buenas prácticas del acceso al agua y saneamiento conllevan a un estado híbrido de acciones entre diversos actores con el objeto de avanzar en el cumplimiento de los Objetivos de Desarrollo Sostenible. En el siguiente gráfico se plasma los elementos que constituyen los criterios normativos y comunes.

\section{Gráfico 3. Buenas prácticas: agua y saneamiento}

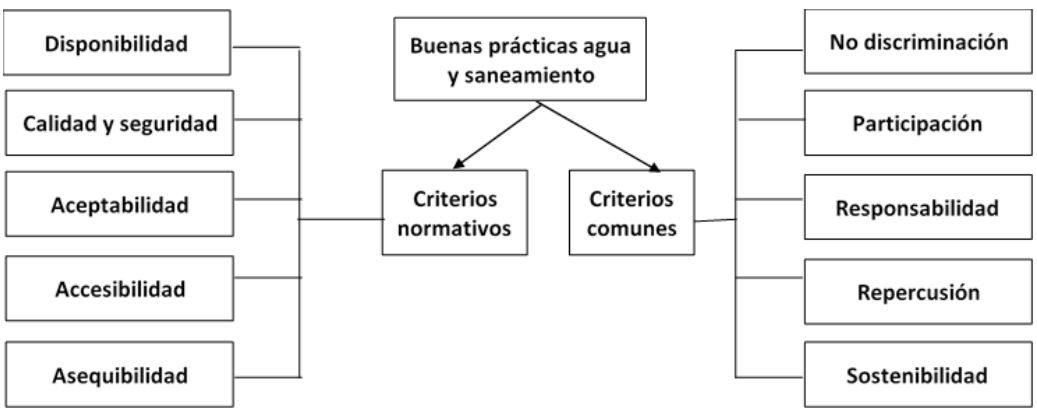

Fuente: Elaboración propia.

De los criterios anteriores prevalecen los valores del sujeto en relación al recurso hídrico, enfocándose en acciones concretas a partir de principios sustantivos para el desarrollo de una vida digna que satisfaga las necesidades básicas de una persona y al mismo tiempo los intereses de bien común de una colectividad en tiempo y espacio. 